\title{
Supply management of high-value components with a credit constraint
}

\author{
Lei Zhao • Floris R. Langendoen · Jan C. Fransoo
}

Published online: 25 June 2011

(C) The Author(s) 2011. This article is published with open access at Springerlink.com

\begin{abstract}
Due to rapid increases in the automotive markets in emerging economies, leading car manufacturers rapidly expand their manufacturing capacity in countries such as China. A certain portion of key performance components however continue to be sourced from developed countries. We study such a manufacturer that imports high-value components from a developed country. There are two available transportation modes: a slow mode with low cost and long and stochastic lead time, and a fast mode with high cost and short and deterministic lead time. Moreover, the manufacturer is subject to a credit constraint that bounds both the inwarehouse inventory and the number of outstanding orders (because it needs to pay for the components in advance). Consequently, the cheapest hedge against demand and supply uncertainty-inventory - is only available to a limited extent and the decision maker must turn to using the fast transportation mode for a much larger share of the orders. We model the manufacturer's ordering policy and study its performance using simulation. Our study shows the adverse effects that the credit limit has on the growth opportunities of such companies in developing countries that import high-value components or other goods from developed countries. We show that especially the reduction in lead time variability can substantially reduce these adverse effects. Realizing that this variability is primarily caused by the import customs procedures, governments in developing economies have a means to assist their local manufacturers.
\end{abstract}

\footnotetext{
L. Zhao

Department of Industrial Engineering, Tsinghua University, Beijing, China e-mail: 1zhao@tsinghua.edu.cn

F. R. Langendoen · J. C. Fransoo $(\bowtie)$

School of Industrial Engineering, Eindhoven University of Technology, Eindhoven, Netherlands e-mail: j.c.fransoo@tue.nl

F. R. Langendoen

e-mail: florislangendoen@gmail.com
} 
Keywords Supply management · Transportation mode $\cdot$ Credit constraint · Inventory

\section{Introduction}

Manufacturing activities in emerging economies have grown significantly over the past decades. A considerable part of the growth of these manufacturing activities are due to the relocation of assembly activities from developed economies with high labor cost such as the United States and Western Europe to low labor cost countries like China. In addition, Western automotive companies have opened new plants in China due to its rapidly growing consumer automotive market. The ownership structure of these automotive assembly plants is diverse. It could be fully owned by the Western parent company; it could be a joint-venture between a Western multinational and a local company in China; or it could be fully outsourced to a local manufacturer in China. Especially in the first years following the investment, many companies take a strategy to initially continue sourcing the main components from the original supplier base in the West. There are several reasons for this remote sourcing. First, using an existing supplier base allows for a much faster ramp-up of the assembly operations. Finding and qualifying hundreds of new suppliers in an environment that is unknown may take considerable time. For example, while Shanghai Volkswagen (a joint-venture since 1985) and First Automotive WorksVolkswagen (FAW-VW, a joint venture since 1991) have individually established supplier bases of more than 400 suppliers in China, with local content ranging from $60 \%$ (Audi) to 94\% (Santana), BMW Brilliance Automotive (a joint venture since 2003) and Beijing Benz-DaimlerChrysler (a joint venture since 2006) each has a supplier base of only around 100 suppliers in China, with $40 \%$ or even $0 \%$ (Mercedes E-class) local content, according to Hermani (2008). Second, companies initially want to ensure that the final assembly operation is running without any problems. Especially for key components with high technology content, companies would not want to take any quality risk. Finally, for key components with core technology, the offshoring companies may choose to continue producing them in high-cost Western countries to protect the intellectual property. These components are transported to China regularly (usually bi-weekly or monthly) via ocean transportation. The transportation lead times are uncertain and usually range from 4 to 6 weeks. The local assembly plants therefore need to keep inventory to hedge against supply uncertainty. Among the imported components, some are of high value such that their inventory requires high capital investment.

The capital investment needed to fund the inventories of these high-value components may pose a challenge for the assembly companies. Western companies shipping products to developing economies typically require substantial guarantee for payment, such as prepayment or letters of credit. A letter of credit is issued by a bank guaranteeing the payment of the components. However, a bank typically only issues a letter of credit if the applying company maintains or freezes a certain balance at the bank as a guarantee. While this already poses a problem for these large automotive companies, the problem is likely to be more substantial for locally 
owned and operated manufacturers using imported high-value components. The problem becomes even more serious for companies operating in countries with relatively weak currencies, such as very young economies in Africa. It is interesting to note that the credit constraint has recently also been experienced by many Western companies during the 2008-2009 financial crisis, a period when it became increasingly difficult for companies to obtain credit to fund their running business.

Ocean transportation has a large lead time variability (Fransoo and Lee 2011) and import clearance in ports of developing economies may take substantial time with high variance (Hausman et al. 2005). FAW-VW keeps the inventory of these highvalue components for 1 week's production. In case of potential shortage, they may resort to a fast transportation mode, for example, air transportation, to ensure its production.

Sculli and $\mathrm{Wu}$ (1981) are the first to model stochastic lead times in the dual sourcing problem. Through a numerical analysis supported by simulation, they provide a set of tables to compute the mean and variance of the normally distributed lead time distribution when two suppliers are used simultaneously to replenish the inventory of a single item. Minner (2003) provides the most recent review of the dual sourcing literature. With regard to models with stochastic lead times he concludes that these models almost exclusively use continuous review (s,Q) policies and determine the optimal number of suppliers, the reorder point, the total order quantity and its allocation among the suppliers (Minner 2003, p. 271).

Essentially these and a series of subsequent models reviewed by Minner (2003) are order splitting models, since they all assume that the decision for the quantity shipped using the high and low cost, regular supply and emergency supply, slow and fast lead time alternatives is made at a single moment of ordering. Thus, the review period is the same for the fast and the slow modes. A recent paper by Kiesmüller et al. (2005) explicitly takes the transportation modal choice into account but maintains the order splitting view on the problem. Duran et al. (2004) studies a continuous review inventory model that allows an order to be expedited some fixed time after the order has been released. They develop a model, optimize using value iteration and verify by simulation. Allon and Van Mieghem (2010) consider a situation with two sources and develop a continuous review policy that they denote as Tailored Base-Surge, in which there is a fixed amount shipped from the cheap, long lead-time supplier and a variable amount, determined by a base stock policy, from the more expensive and responsive supply source.

In this paper, we recognize that the review periods of ordering for the fast mode and the slow mode are generally not identical in real life. For instance, an ocean liner service between the Hamburg port in Germany and the Tianjin port in China is at best available with a weekly frequency, while cargo flights between Frankfurt and Beijing fly on a daily frequency. This difference in review periods substantially constrains using any of the existing models in our setting.

We investigate the ordering behavior of companies that need high-value components with long distance transportation and subject to a credit constraint. The essential trade-off for these companies is whether to use a cheaper means of transportation (usually ocean transportation), which incurs a lower transportation cost but has a larger variance in the lead time and therefore requires a much higher 
capital investment, or a more expensive mode of transportation (air transportation), which incurs a substantially higher transportation cost but requires a considerably lower capital investment. We show that (tight) credit limit actually drives the decision maker to a much higher total expected operating cost, thus providing either a much smaller profit margin or inhibiting growth. Furthermore, we show that efforts to reduce transportation lead time uncertainty can considerably alleviate the pressure of capital investment on the importers (i.e., the manufacturing companies in the developing countries). This indicates the important role that governmental authorities can play, for example, by providing short and reliable import customs services.

We are interested in modeling the setting that resembles closest to the supply situation of an assembly operation in a developing economy ordering high-value key components overseas. This is characterized by two modes of transportation, stochastic lead times, and different review periods. We are unaware of any study that actually combines these characteristics in a single paper. Moreover, our modeling of the cash flow consequences is different from any of the previous models. We use simulation to investigate our model's properties and to develop insights.

Simulation has been used extensively to explore new and complex settings of important industry problems before theoretical analysis is being conducted on more restricted versions of these complex settings. For instance, Hayya et al. (1987) studies the two supplier order splitting model using simulation, and recently many new problems analyzing disruptions due to globalization of supply chains have been studied by simulation (Tang 2006).

The remainder of this paper is organized as follows. In the next section, we develop the mathematical model that fully describes the supply chain and the ordering policy. Then, in Sect. 3, we describe the simulation model and the experimental design, followed by presentations and discussions of the experiment results. We conclude in Sect. 4.

\section{Model}

We consider the situation where a manufacturer outsources the production of a highvalue component to a supplier (Fig. 1). The supplier is located far away from the manufacturer, which means that the lead time from ordering the components to the time when the components are available at the manufacturer's site is long. Furthermore, the lead time is uncertain when transporting the components by ocean (which we call "the slow transportation mode"). In emergency, the manufacturer can also order the components that are shipped by air ("the fast transportation mode"). The fast transportation mode has a much shorter and deterministic lead time, but incurs higher transportation cost.

The manufacturer faces stochastic demand. Unfulfilled demand in a period is backordered and charged with a backorder cost. The long lead time results in a considerable financial investment of the manufacturer, because a down payment to the supplier needs to be made before the ordered components are shipped. 


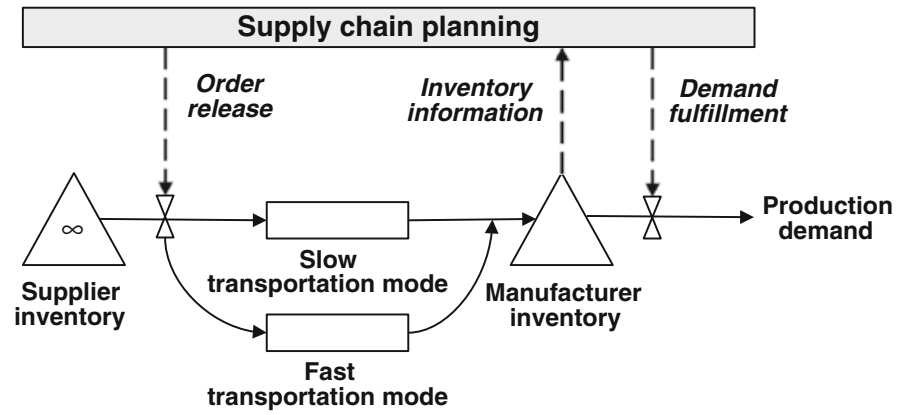

Fig. 1 The supply chain structure

Therefore, as discussed above, we model not only the relevant operational costs (transportation, inventory, and backorder), but also the cash flows.

The manufacturer uses a supply chain planning system to order components. De Kok and Fransoo (2003) discuss the supply chain planning problem extensively. Our paper is based on their discussion of mathematical programming models. However, our work is different in that we consider two order release decisions (orders using the slow and fast transportation modes) with different review periods and the lead time of the slow transportation mode is stochastic. Furthermore, we introduce a credit constraint to capture the impact of a financial investment constraint on the order release strategy. In this study, we assume that the system does not have any capacity restrictions.

\subsection{Transportation modes and inventory policies}

In this subsection, we describe the two transportation modes and the corresponding inventory policies. We define:

$D(t) \quad$ Demand in period $t$.

$D\left(t_{1}, t_{2}\right) \quad$ Realized demand in periods $\left(t_{1}, t_{2}\right)$.

$\hat{D}_{t}\left(t_{1}, t_{2}\right) \quad$ Forecast made at the start of period $t$ for the demand in periods $\left(t_{1}, t_{2}\right)$.

$p(t) \quad$ Total amount of components that become available at the manufacturer's site at the start of period $t, p(t)=p_{1}(t)+p_{2}(t)$.

$p_{1}(t) \quad$ Components shipped by the slow transportation mode that become available at the manufacturer's site at the start of period $t$.

$p_{2}(t) \quad$ Components shipped by the fast transportation mode that become available at the manufacturer's site at the start of period $t$.

$X(t) \quad$ Physical inventory at the start of period $t$, immediately before the receipt of $p(t)$.

$B(t) \quad$ Backorder at the start of period $t$, immediately before the receipt of $p(t)$.

$O(t) \quad$ Total outstanding orders at the start of period $t$, immediately before the receipt of $p(t)$.

$O_{2}(t) \quad$ Outstanding orders that are shipped by the fast transportation mode, at the start of period $t$, immediately before the receipt of $p(t)$. 
$J(t) \quad$ Net inventory at the start of period $t$, immediately before the receipt of $p(t) . J(t)=X(t)-B(t)$.

$Y(t) \quad$ Inventory position at the start of period $t$, immediately before the receipt of $p(t) . Y(t)=X(t)-B(t)+O(t)$.

$\hat{Y}_{t}\left(t_{1}\right) \quad$ Forecast made at the start of period $t$ for the inventory position at the start of period $t_{1}$, immediately before the receipt of $p\left(t_{1}\right)$.

$r_{1}(t) \quad$ Part/component order released for the slow transportation mode at the start of period $t$, immediately after the receipt of $p(t)$.

$r_{2}(t) \quad$ Part/component order released for the fast transportation mode at the start of period $t$, immediately after the receipt of $p(t)$.

$r(t) \quad$ Total part/component order released at the start of period $t$, immediately after the receipt of $p(t)$. That is, $r(t)=r_{1}(t)+r_{2}(t)$.

$L_{1}(t) \quad$ Lead time (in periods) of an order released at the start of period $t$ when using the slow transportation mode.

$L_{p} \quad$ Expected lead time (in periods) of the slow transportation mode.

$R \quad$ Review period (in periods) of the slow transportation mode.

$L_{2} \quad$ Lead time (in periods) of the fast transportation mode, which is constant.

SS Safety stock of the slow transportation mode.

$S_{1} \quad$ Base stock level of the slow transportation mode.

$S_{2} \quad$ (Emergency) base stock level of the fast transportation mode.

The material balance constraint is

$$
X(t+1)-B(t+1)=X(t)-B(t)-D(t)+p(t) .
$$

\subsubsection{Orders for the slow (regular) transportation mode}

We assume that the manufacturer can release an order for the slow transportation mode in every $R$ periods. The lead time of an order released at the start of period $t$ when using the slow transportation mode, $L_{1}(t)$, is stochastic and is in integer multiples of periods: components ordered at the start of period $t$ will be available at the start of period $t+L_{1}(t)$. It is reasonable to assume that the expected lead time of the slow transportation mode $L_{p}$ is longer than the review period $R$, i.e., $L_{p} \geq R$. For example, a Chinese automotive manufacturer may review its imported high-value component inventory every 2 weeks, while the ocean transportation from its European supplier may take 4-6 weeks to arrive.

The order quantity released in each review period follows the following policy:

$$
r_{1}(t)=\left(S S+\hat{D}_{t}\left(t, t+L_{p}+R-1\right)-Y(t)\right)^{+}, \quad t=R, 2 R, \ldots
$$

Note that $\hat{D}_{t}\left(t, t+L_{p}+R-1\right)$ is the demand forecast made at the start of period $t$ for periods $\left[t, t+L_{p}+R-1\right]$ and the safety stock $S S$ is an adjustment to the demand forecast. Equation 2 is essentially a demand forecast adjusted base stock policy with $S_{1}=S S+\hat{D}_{t}\left(t, t+L_{p}+R-1\right)$.

In Fig. 2, we illustrate that, the order quantity $r_{1}(t)$ includes three components: (1) the compensation on the differences between the realized and forecasted 

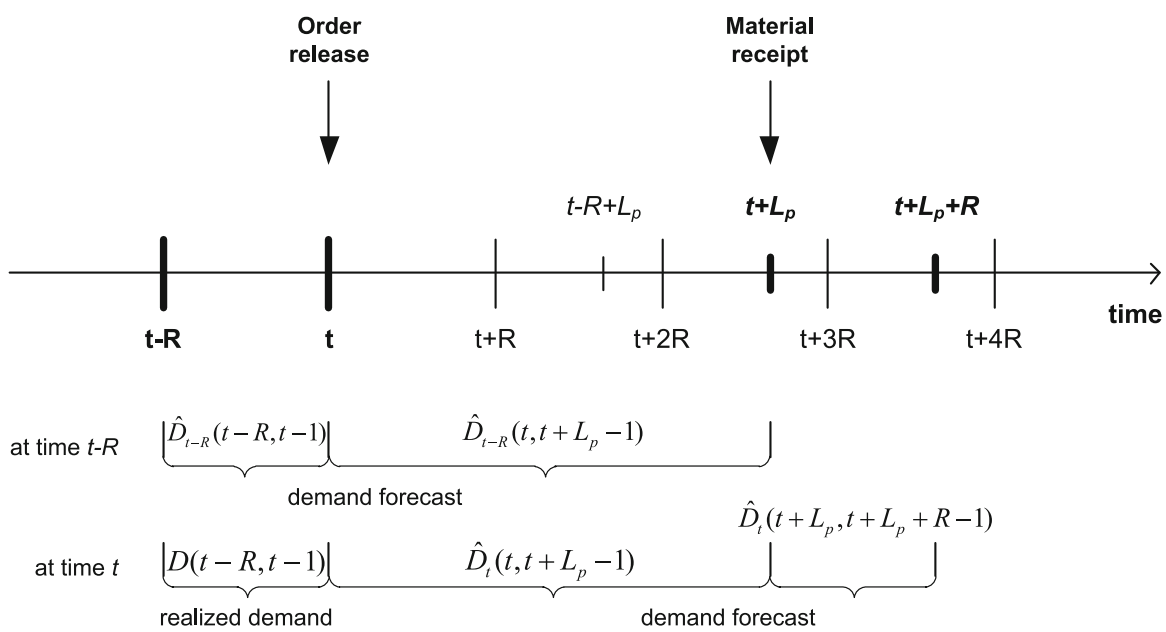

Fig. 2 Order release decision (slow transportation mode)

demands of periods $[t-R, t]$, (2) the update of demand forecast for periods $\left[t, t+L_{p}-1\right]$, and (3) the demand forecast for periods $\left[t+L_{p}, t+L_{p}+R-1\right]$.

The order quantity released at the start of period $t$ can be decomposed into three parts:

1. The difference between the realized demand in periods $[t-R, t-1]$ and the demand forecast made at the start of period $t-R$ for periods $[t-R, t-1]$. That is, in review period $t$, we compensate the difference between the realized and forecasted demands of periods $[t-R, t]$ by ordering $D(t-R, t-1)-\hat{D}_{t-R}(t-R, t-1)$. On the other hand, when $Y(t-R) \leq S S+\hat{D}_{t-R}\left(t-R, t+L_{p}-1\right)$, the forecasted inventory position at the start of period $t$ made at the start of period $t-R$ is

$$
\begin{aligned}
\hat{Y}_{t-R}(t) & =S S+\hat{D}_{t-R}\left(t-R, t+L_{p}-1\right)-\hat{D}_{t-R}(t-R, t-1) \\
& =S S+\hat{D}_{t-R}\left(t, t+L_{p}-1\right) .
\end{aligned}
$$

Therefore, the difference between the forecasted and realized inventory positions at the start of period $t$ is then equal to the difference between the forecasted and realized demands in periods $[t-R, t-1]$ :

$$
\begin{aligned}
D(t-R, t-1)-\hat{D}_{t-R}(t-R, t-1) & =\hat{Y}_{t-R}(t)-Y(t) \\
& =S S+\hat{D}_{t-R}\left(t, t+L_{p}-1\right)-Y(t) .
\end{aligned}
$$

2. The difference between the demand forecast of periods $\left[t, t+L_{p}-1\right]$ made at the start of period $t-R$ and period $t$.

The demand forecast for periods $\left[t, t+L_{p}-1\right]$, made at the start of period $t-R$, is updated at the start of period $t$. We compensate for the difference between the demand forecasts made in the two different periods by ordering $\hat{D}_{t}\left(t, t+L_{p}-1\right)-\hat{D}_{t-R}\left(t, t+L_{p}-1\right)$. 
3. The demand forecast for periods $\left[t+L_{p}, t+L_{p}+R-1\right]$ that needs to be ordered at the start of period of $t: \hat{D}_{t}\left(t+L_{p}, t+L_{p}+R-1\right)$.

By summing up the three parts, we obtain the ordering policy for the slow transportation mode as in Eq. 2. The demand forecast adjusted base stock $S_{1}=$ $S S+\hat{D}_{t}\left(t, t+L_{p}+R-1\right)$ is used to cope with uncertainties in demand and supply lead time. Note that in Eq. 2, the reference stock level $S S$ can be negative since orders are likely to be outstanding.

\subsubsection{Orders for the fast (emergency) transportation mode}

When the physical inventory becomes lower than the emergency base stock level $S_{2}$, the manufacturer places an emergency order for the fast transportation mode, for example, air transportation. We assume that the lead time for the fast transportation mode, $L_{2}$, is constant and is also in integer multiple of periods. At the moment of releasing an emergency order, the manufacturer does not know the exact delivery dates of the previously placed orders using the slow transportation mode.

The emergency order quantity should be sufficient to raise the net inventory and outstanding orders for previously made emergency orders to the base stock level:

$$
r_{2}(t)=\left(S_{2}-J(t)-O_{2}(t)\right)^{+}, \quad t=0,1,2, \ldots
$$

Therefore, the ordered quantity that becomes available at the start of period $t$ is

$$
\begin{gathered}
p_{1}(t)=\sum_{\left\{k \mid k+L_{1}(k)=t\right\}} r_{1}\left(t-L_{1}(k)\right), \\
p_{2}(t)=r_{2}\left(t-L_{2}\right) .
\end{gathered}
$$

\subsection{Operational costs and cash flows}

Next, we introduce the calculation of the operational cost and the cash flows. We define

$v \quad$ Unit component value before shipping (\$).

$h \quad$ Inventory holding cost (\$/unit/period).

$b \quad$ Backorder cost (\$/unit/period).

$c_{1} \quad$ Shipping cost for the slow transportation mode (\$/unit).

$c_{2} \quad$ Shipping cost for the fast transportation mode (\$/unit).

$C(t) \quad$ Total operational cost in period $t$.

$I N(t) \quad$ Total cash inflow in period $t$.

OUT $(t)$ Total cash outflow in period $t$.

$C P(t) \quad$ The cash position at the start of period $t$, immediately before the receipt of ordered components $p(t)$.

$\gamma \quad$ Down payment before shipment from the supplier, as a percentage of the order value.

$\tau \quad$ Credit level (on the maximal negative cash position). 


\subsubsection{Operational cost}

The operational cost consists of the inventory holding cost, backorder cost, and transportation cost.

$$
C(t)=h \cdot X(t+1)+b \cdot B(t+1)+c_{1} \cdot r_{1}(t)+c_{2} \cdot r_{2}(t) .
$$

We measure the performance of the manufacturer by the expected average operational cost during the (finite) planning horizon $T$, that is,

$$
\min E\left[\sum_{t=0}^{T} C(t) / T\right] .
$$

\subsubsection{Cash flows}

When an order is released to the supplier, a down payment (a percentage $\gamma$ of the total value of the ordered components) has to be made immediately. In this study, we assume that the component value remains the same from the supplier to the manufacturer and to the customer, to avoid an extensive discussion on allocating cost and dealing with profit margins.

The cash inflow in period $t$ equals the total value of the amount of backorders and demand fulfilled in period $t$. The cash outflow in period $t$ includes the down payment of orders released at the start of period $t$ and the payment of the remaining amount (after down payment) of previous orders received at the start of period $t$.

$$
\begin{gathered}
I N(t)=v \cdot[D(t)+B(t)-B(t-1)], \\
O U T(t)=\gamma \cdot v \cdot r(t)+(1-\gamma) \cdot v \cdot p(t) .
\end{gathered}
$$

The flow balance constraint for the cash position is

$$
C P(t+1)=C P(t)+I N(t)-O U T(t) .
$$

We constrain the maximal negative cash position of the system to be within a credit level $\tau$. The cash flow/credit constraint can be described as

$$
-C P(t) \leq \tau \text {. }
$$

We can then define the component acquisition problem with the credit constraint as

$$
\begin{gathered}
\min E\left[\sum_{t=0}^{T} C(t) / T\right] \\
\text { s.t. } \quad-C P(t) \leq \tau .
\end{gathered}
$$

The decision variables are the reference stock level $S S$ for the slow transportation mode and the emergency base stock level $S_{2}$ for the fast transportation mode, i.e., the inventory policy for both transportation modes. 


\section{Simulation experiment}

To explore the impact of the credit constraint on the high-value component inventory policies and the system operational cost, we build the simulation model for the manufacturer's high-value component supply management system using AnyLogic University 6.5.1. We have set the length of the warm-up period, the run length, and the number of replications in accordance with common best practices (Law and Kelton 2000). For each set of parameters, we use the OptQuest optimization engine embedded in the software to solve (14), to find the candidate inventory policies for the slow and fast transportation modes. We then use a simplified "cleanup" procedure (Nelson 2010; Hong and Nelson 2009) to select the best inventory policy, to address the variability issue in optimization via simulation (OvS).

In the simulation model, we assume that the stochastic demand faced by the manufacturer is stationary and only changes slightly between periods, and model the demand process as a second-order autoregressive process:

$$
D(t)=\delta+\phi_{1} D(t-1)+\phi_{2} D(t-2)+\epsilon_{t},
$$

where $\epsilon_{t} \sim N\left(0, \sigma_{\epsilon}^{2}\right)$. The stationary conditions are

$$
\begin{aligned}
& \phi_{1}+\phi_{2}<1, \quad \phi_{2}-\phi_{1}<1, \quad\left|\phi_{2}\right|<1, \quad \phi_{1}^{2}+\phi_{2}^{2}<1, \\
& E[D(t)]=\frac{\delta}{1-\left(\phi_{1}+\phi_{2}\right)}, \quad \text { and } \quad \sigma^{2}(D(t))=\frac{\sigma_{\epsilon}^{2}}{1-\left(\phi_{1}^{2}+\phi_{2}^{2}\right)} .
\end{aligned}
$$

Because of the stationarity assumption and the long forecast time, we assume that the demand forecast is made based on the expected demand per period and the expected number of forecast periods:

$$
\hat{D}_{t}\left(t, t+L_{p}+R-1\right)=\left(L_{p}+R\right) \cdot E[D(t)] .
$$

\subsection{Experimental design}

We are specifically interested in investigating the impact of the credit constraint. Hence, we divide our experimental design into two sets, namely, decision making without the credit constraint and decision making with the credit constraint. We anticipate that having the credit constraint will force the decision maker to make more use of the fast (air) transportation mode. This will lead to an increase in the total expected operational cost. We are interested in the magnitude of this effect to assert whether it is worthwhile to address this issue separately when making supply chain design decisions, for example, on inventory policies, transportation modes.

Moreover, we are interested in understanding the effects of the different parameter settings, in particular the backorder cost, the cost of the slow and fast transportation modes, the lead time of the slow transportation mode, and the variance in demand. To separate out the effect of the stochastic transportation lead time for the slow (ocean) mode, we run our set of experiments both for the case of a stochastic ocean transportation lead time and for the case of a deterministic transportation lead time. 
Table 1 Parameter setting in the base case

\begin{tabular}{lll}
\hline Parameter & & Value \\
\hline$v$ & Component value & 500 \\
$h$ & Holding cost & 0.20 per unit per day \\
$b$ & Backorder cost & 1,000 per unit per day \\
$c_{1}$ & Transportation cost: slow mode & 5 per unit \\
$c_{2}$ & Transportation cost: fast mode & 50 per unit \\
$\gamma$ & Down payment & $20 \%$ \\
\hline
\end{tabular}

For our base case, we set the manufacturer to review its inventory daily. The slow transportation occurs only twice a month $(R=15$ days $)$, while fast transportation is available daily. The stochastic lead time of the slow transportation mode follows a triangular distribution $\left(L_{1}(t) \sim\right.$ Triang $\left.[30,40,60]\right)$, and the deterministic lead time of the fast transportation mode takes 2 days $\left(L_{2}=2\right)$. The demand across all experiments is modeled as a second-order autoregressive process as discussed above, with $\delta=10, \phi_{1}=0.5, \phi_{2}=0.4$ and $\sigma_{\epsilon}=3$. The remaining parameters of the base case are displayed in Table 1. Note that the high backorder cost are common in the automotive industry due to the production line stoppage caused by component shortages.

\subsection{Experimental results}

Table 2 shows the base case results for different levels of the safety stock $(S S)$ of the slow transportation mode. The results show that the backorder cost drives the decision towards either having high inventory or high transportation cost for the fast mode. Moreover, at the optimal safety stock level, only about $1 \%$ of the volume is transported using the fast transportation mode. This finding is in line with earlier findings such as Kiesmüller et al (2005), who finds that even under adverse conditions (for instance, high demand variation), a fast transportation mode is hardly used and keeping inventory is preferable for any realistic setting of inventory and fast mode transportation cost. We conjecture that their findings can thus be extended to situations such as ours when the review period of the slow mode is

Table 2 Selection of base case results (all cost figures are expressed in average period cost)

\begin{tabular}{llllllll}
\hline $\begin{array}{l}\text { Safety } \\
\text { stock } \\
(S S)\end{array}$ & $\begin{array}{l}\text { Total } \\
\text { cost } \\
(\$)\end{array}$ & $\begin{array}{l}\text { Backorder } \\
\text { cost }(\$)\end{array}$ & $\begin{array}{l}\text { Holding } \\
\text { cost }(\$)\end{array}$ & $\begin{array}{l}\text { Transport. } \\
\text { cost: slow } \\
\text { mode }(\$)\end{array}$ & $\begin{array}{l}\text { Transport. } \\
\text { cost: fast } \\
\text { mode }(\$)\end{array}$ & $\begin{array}{l}\text { Mean cash } \\
\text { position } \\
(\mathrm{M} \$)\end{array}$ & $\begin{array}{l}\text { Max. neg. } \\
\text { cash position } \\
(\mathrm{M} \$)\end{array}$ \\
\hline 2,400 & 1,121 & 0 & 621 & 500 & 0 & -1.985 & -2.850 \\
$1,200^{\mathrm{a}}$ & 938 & 0 & 398 & 495 & 52 & -1.404 & -2.287 \\
0 & 1,236 & 1 & 246 & 446 & 543 & -1.002 & -1.977 \\
$-1,200$ & 1,872 & 2 & 160 & 366 & 1,344 & -0.721 & -1.682 \\
$-2,400$ & 2,642 & 3 & 98 & 274 & 2,268 & -0.491 & -1.359 \\
\hline
\end{tabular}

\footnotetext{
${ }^{\text {a }}$ The optimal safety stock level
} 
longer than that of the fast mode and when the lead time of the slow mode is stochastic while that of the fast mode is deterministic. Essentially, the decision maker can afford this because the holding cost of inventory is relatively low compared to other expenses, especially the backorder cost and the cost difference between the fast and the slow transportation modes. This goes however at the expense of an increased negative cash position. Both the average negative cash position and the maximum negative cash position increase considerably with a higher safety stock level. Note that in the results here, we assume a $20 \%$ down payment and a payment of the remaining invoice in the period of goods receipt. In many cases in real life a letter of credit needs to be issued, which is effectively the same as a 100\% down payment, further worsening the cash position. Our experiments also show that the same effects hold in the case when the lead time of the slow mode is deterministic, although obviously the total cost is lower.

Next, we turn to the set of experiments where we impose the negative cash position/credit limit. Here, we show only the optimized setting of parameters for each credit limit. We vary the credit limit between 500,000 and 2 million in increments of 500,000. The results are shown in Fig. 3, which also displays the results for the situation in which no cash position constraint exists ("INF"). Note also that we omit the negative sign in the credit limits.

Figure 3 very well illustrates the trade-off that the companies under study are faced with. It clearly shows that when there is a limit on the negative cash position, the decision maker is forced to reduce its inventory, and hence will substantially increase its operating cost due to having to use the expensive fast transportation mode to retain its service level. The credit constraint has a substantial effect on profitability. Moreover, the cost effect gets larger when the demand variance increases (we will discuss next). Consequently, these companies are likely to reduce their service levels, in order to limit the impact of the cash position constraint on the total operational cost.

We can observe the impact of cash position constraint more clearly in Tables 3, 4 and 5, where we have investigated the consequences of varying parameter settings, namely, (1) smaller backordering cost, (2) higher holding cost, (3) higher cost of

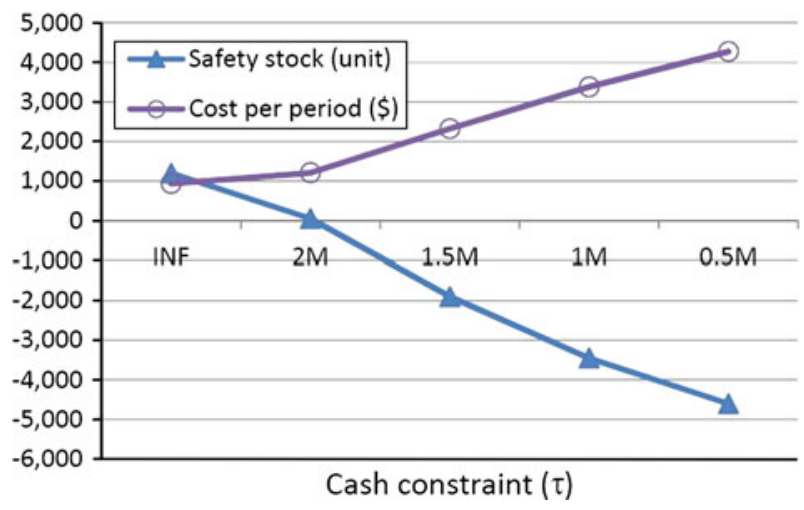

Fig. 3 Impact of the credit constraint on the optimal safety stock level and the total cost 


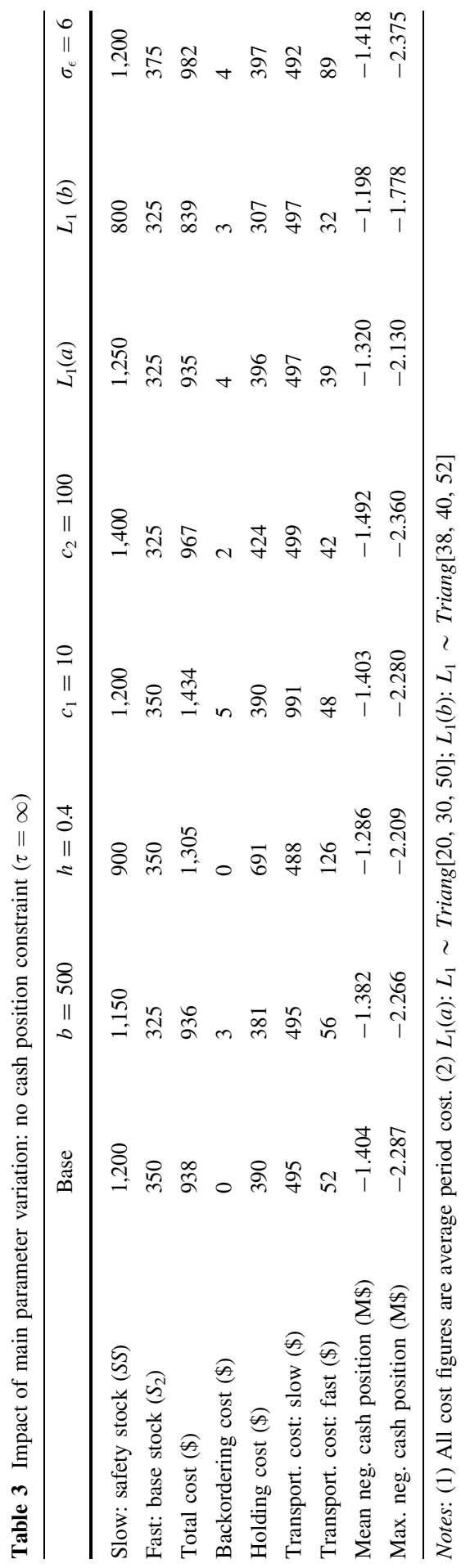




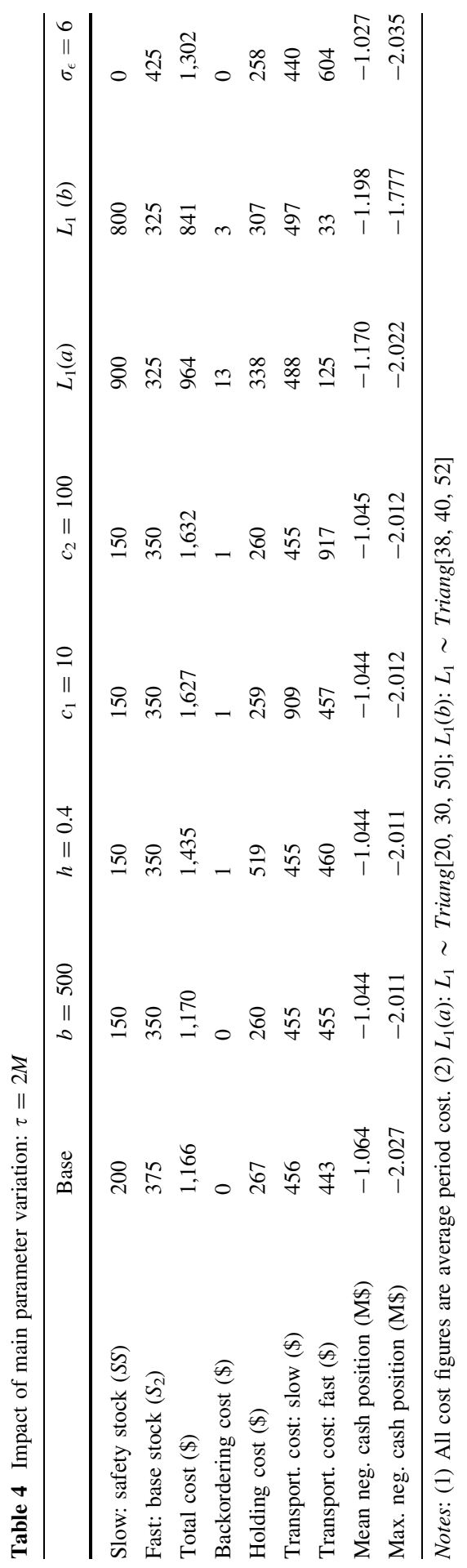




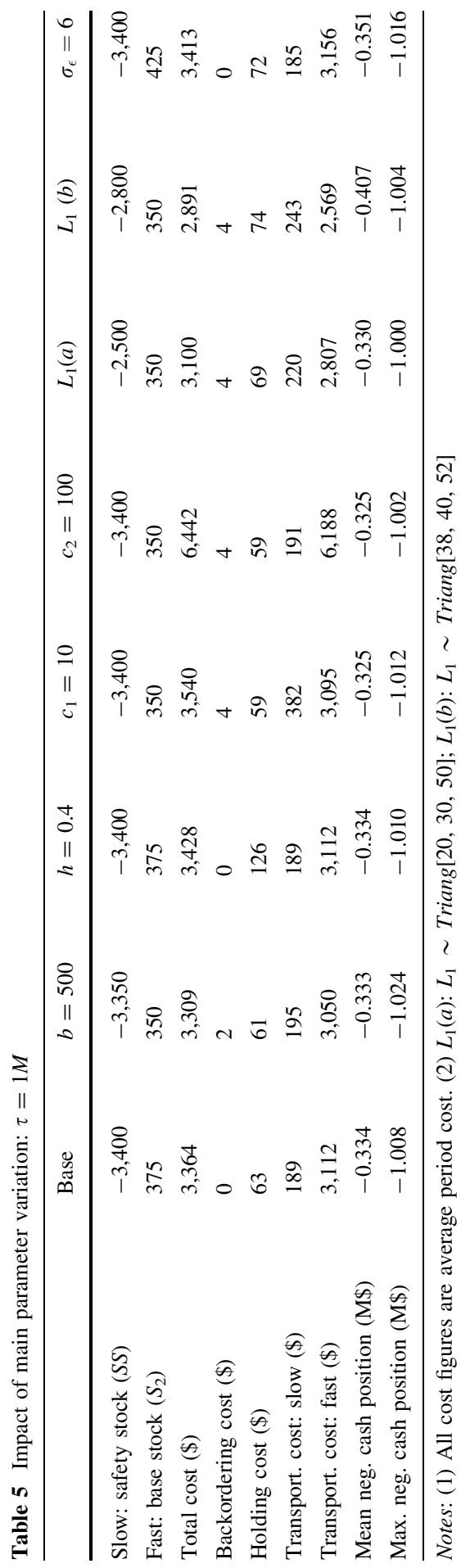


slow transportation, (4) higher cost of fast transportation, (5) shorter expected lead time of the slow transportation mode, (6) smaller lead time variance of the slow transportation mode, and (7) larger demand variance. In all cases, we vary only one parameter in comparison to the base case. Especially, we keep the slow transportation lead time variance unchanged when we reduce its expected value, and vise versa. For each parameter setting, we obtain the candidate inventory policies by the embedded OptQuest optimization engine of AnyLogic and then select the best one via simulation evaluation of the candidate policies with more replications. The results in Tables 3, 4 and 5 are the average of 300 replications under each parameter setting, and represent an illustration of the main effects. All main effects are significant.

In Tables 4 and 5, we observe slight violations of the maximum negative cash positions over the credit constraint. This is due to the fact that the optimization via simulation $(\mathrm{OvS})$ procedure is based on the actual sample of 30 replications, and results presented in these two tables are based on the simulation evaluation of 300 replications, where we are more likely to observe violations in some extreme cases. However, the violations range from zero to $2.4 \%$ and are on average $1 \%$, which is acceptable practically. Note also that the mean negative cash positions are well within the credit limit.

We observe that, in line with our discovery in Fig. 3, the credit constraint poses a significant limit on the safety stock level, resulting lower holding cost and slow transportation cost. On the other hand, to maintain a certain service level, the decision maker resorts to emergency deliveries with much higher cost. The results hold for the cases of varied parameters on backorder cost, holding cost, slow and fast transportation cost, and demand variability. Note that increasing the unit cost of the fast transportation mode $\left(c_{2}=100\right)$ under the credit constraint ( $\tau=1 M$ and $\tau=2 M$ ) almost doubles the total cost due to the significant share of the fast transportation mode in the operations (Tables 4,5), while it has little impact on the total cost when the credit constraint is absent (Table 3 ).

However, it is worth noticing that reducing the slow transportation lead time, especially its variance, substantially impacts the operational cost and cash position, recognized from the observations that the credit constraint of $\tau=2 M$ has small impact on the safety stock level when reducing the lead time expectation and no impact when reducing the variance. That is, lead time and especially variance reduction relax the limit on the safety stock posed by the credit constraint, and hence a higher service level can be maintained under a narrower credit constraint, without resorting much to emergency deliveries. Under the tighter credit constraint $(\tau=1 M)$, reduction in lead time variance has more significant impact on mitigating the limit on safety stock posed by the credit constraint than reduction in lead time expectation does.

\section{Conclusions}

In this paper, we have addressed the inventory/ordering problem of high-value components with stochastic transportation lead time and under a credit constraint. 
Assembly companies in developing countries such as the automotive industry in China are usually faced with these characteristics that cannot be analyzed with existing models. In fact, the two characteristics combined prohibit us from obtaining analytical results. Hence, we have resorted to simulation to obtain first insights into this problem. We have formulated the simulation model as close as possible to the actual observations that we have made in this type of companies. Using the OptQuest optimization engine embedded in AnyLogic, we find the candidate inventory policies, evaluate them, and select the best one using a simplified "cleanup procedure."

When considering the optimal decisions made without the credit constraint, we find similar results to earlier numerical work, namely that the fast transportation mode is hardly used. The optimal decision maker will hedge against demand and transportation lead time uncertainty by having sufficient inventory. In crosscontinental sourcing, the slow transportation mode is usually ocean and the fast mode is air, providing a huge cost difference between the two modes, which can be easily hedged by taking some extra safety stock. It is known from earlier work that the usage share of the fast mode is small and is mainly determined by the lead time differential and the demand uncertainty. We therefore do not address this trade-off further in our paper.

Introducing the credit constraint changes the optimal decision substantially. The credit constraint bounds both the inventory and the size of outstanding orders. Consequently, the cheapest hedge against demand and supply uncertaintyinventory-is only available to a limited extent and the decision maker must turn to using the fast transportation mode for a much larger share of the component orders. The fast mode share - and hence the total operational cost-increases sharply if the negative cash position (associated with the demand during the lead time of the slow transportation mode) is limited by the credit constraint. In this case, the fast mode is necessary to limit the negative cash position even for perfectly predictable demand.

Our study shows the adverse effects that a credit constraint has on the growth opportunities faced by companies that imports high-value components or other goods from overseas. We show that in order to maintain a high service level, these companies need a substantial credit. If this credit is not available or limited, either this will affect their profitability or they will be forced to reduce the service level. Generally speaking it is the service level that suffers mostly, as companies simply cannot afford the high operational cost associated with operating at a high service level under the credit constraint. Further, we show that reduction in the supply lead time and especially its variance can substantially improve the performance. It is known that the delay and high variance in customs processing times are important sources of prolonged supply lead time and its variability. Hence, an important role for governments that want to facilitate rapid economic growth goes beyond guaranteeing letter of credit. Substantial improvements in the business climate can be reached by reducing customs processing time and its variability.

Our paper proposes a new problem and models it in a fairly rich way using simulation. Challenges remain to obtain analytical results that provide structural insights into the trade-offs. Although we believe simplification of our model is possible, some of the key characteristics need to be maintained, both to maintain the 
insights, and to attain the development of a decision model and logic that can actually be deployed. We therefore encourage further research in this area of decision making for companies in developing economies.

Acknowledgments This research was supported by Projects No. 70771053 and No. 71031005 from The National Natural Science Foundation of China.

Open Access This article is distributed under the terms of the Creative Commons Attribution Noncommercial License which permits any noncommercial use, distribution, and reproduction in any medium, provided the original author(s) and source are credited.

\section{References}

Allon G, Van Mieghem JA (2010) Global dual sourcing: tailored base-surge allocation to near- and offshore production. Manage Sci 56(1):110-124

De Kok AG, Fransoo JC (2003) Planning supply chain operations: definition and comparison of planning concepts. In: Graves SC, De Kok AG (eds) Supply chain management: design, coordination and operation (Handbooks in Operations Research and Management Science). vol 11, Elsevier, Amsterdam, pp 597-675

Duran A, Gutierrez G, Zequeira RI (2004) A continuous review inventory model with order expediting. Int J Prod Econ 87(2):157-169

Fransoo JC, Lee CY (2011) Ocean container transport: an underestimated and critical link in global supply chain performance. Prod Oper Manag, in press

Hausman WH, Lee HL, Subramanian U (2005) Global logistics indicators, supply chain metrics, and bilateral trade patterns. Policy research working paper 3773, World Bank

Hayya JC, Christy DP, Pan A (1987) Reducing inventory uncertainty: a reorder point system with two vendors. Prod Invent Manage 28(2):43-49

Hermani JP (2008) Supply chain risk management of German carmakers producing in china. Master's thesis, Department of Industrial Engineering, Tsinghua University, China

Hong LJ, Nelson BL (2009) A brief introduction to optimization via simulation. In: Rossetti MD, Hill RR, Johansson B, Dunkin A, Ingalls RG (eds) Proceedings of the 2009 winter simulation conference, Institute of Electrical and Electronic Engineers, Piscataway, pp 75-85

Kiesmüller GP, De Kok AG, Fransoo JC (2005) Transportation mode selection with positive manufacturing lead time. Transp Res Part E Log Transp Rev 41(6):511-530

Law AM, Kelton WD (2000) Simulation modeling and analysis. McGraw-Hill series in Industrial Engineering and Management Science, McGraw-Hill, New York

Minner S (2003) Multiple-supplier inventory models in supply chain management: a review. Int J Prod Econ 81-82:265-279

Nelson BL (2010) Optimization via simulation over discrete decision variables. In: Hasenbein JJ (eds) Tutorials in operations research: risk and optimization in an uncertain world. INFORMS, Hanover, pp 193-207

Sculli D, Wu SY (1981) Stock control with two suppliers and normal lead times. Int J Oper Res Soc 32(11):1003-1009

Tang CS (2006) Perspectives in supply chain risk management. Int J Prod Econ 103(2):451-488

\section{Author Biographies}

Lei Zhao is an Associate Professor in the Department of Industrial Engineering at Tsinghua University, China. He received his PhD in Systems and Industrial Engineering at the University of Arizona in 2005. Professor Zhao's research focuses on modeling and algorithm development in stochastic optimization (approximate dynamic programming, stochastic programming, etc.) and large scale optimization, with 
applications in supply chain (risk) management, urban logistics management, and healthcare services and operations management.

Floris R. Langendoen is Unit Manager Industry at Voorbij Prefab Beton. He holds an MSc in Operations Management \& Logistics from Eindhoven University of Technology, Netherlands. He conducted this work as a student at Eindhoven University of Technology.

Jan C. Fransoo is Professor of Operations Management \& Logistics in the School of Industrial Engineering at Eindhoven University of Technology in the Netherlands. He holds an MSc in Industrial Engineering and a $\mathrm{PhD}$ in Operations Management \& Logistics from the same school. His current research addresses a variety of problems in supply chain management, including intermodal transportation, inventory management, carbon emissions, and distribution in emerging economies. Professor Fransoo has published over 60 papers in international journals such as Management Science, Manufacturing \& Service Operations Management, Journal of Operations Management, Production and Operations Management, and OR Spectrum, and serves on the editorial board of 6 academic journals, including FSM Journal. He is co-editor of the Springer volume "Behavioral Operations in Planning and Scheduling". 